\title{
In Vitro Models to Study Candida Albicans Biofilms
}

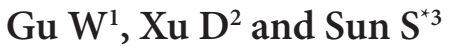

${ }^{1}$ School of Pharmaceutical Sciences, Shandong University, Shandong Province, People's Republic of China ${ }^{2}$ Department of Nephrology, Qianfoshan Hospital Affiliated to Shandong University, People's Republic of China ${ }^{3}$ Department of Pharmacy, Qianfoshan Hospital Affiliated to Shandong University, Shandong Province, People's Republic of China

${ }^{*}$ Corresponding author: Sun S, Department of Pharmacy, Qianfoshan Hospital Affiliated to Shandong University, Jinan, Shandong Province, People’s Republic of China, 250014, E-mail: sunshujuan888@163.com Citation: Gu W, Xu D, Sun S (2015) In Vitro Models to Study Candida Albicans Biofilms. J Pharm Drug Devel 3(3): 301. doi: 10.15744/2348-9782.3.301

Received Date: March 23, 2015 Accepted Date: June 22, 2015 Published Date: June 24, 2015

\begin{abstract}
Biofilm is a common mode of fungal growth in clinical infection and Candida albicans is one of the species that are the most frequently associated with biofilm infection which has a significant impact on morbidity and mortality. In the mode of biofilm, C. albicans tends to display high resistance to body immunity and antimicrobial agents. Models of C. albicans biofilms are very powerful tools that can help researchers to study and control biofilms-associated infection. Thus, there has long been interest in developing models of $C$. albicans biofilms. Here, we review recent studies that attempted to establish in vitro models of $C$. albicans biofilms. The studies of the mechanism of biofilm formation and its structure, and the susceptibility test of some antifungal agents have used the models to characterize the biofilms. Models of C. albicans biofilms do seem to reflect important aspects of fungal infection, and will likely provide critical insights into the molecular and organismic mechanisms as well as novel therapeutic interventions for Candida infection.

Keywords: Antifungal susceptibility test; Biofilm formation study; Laboratory models
\end{abstract}

\section{Introduction}

Biofilm is defined as microbial communities encased in a matrix of extracellular polymeric substances [1]. It is a common mode of fungal growth in nature and is also important in clinical infections, especially infections associated with medical device [2]. Fungal biofilms typically develop over five sequential steps: (1) the adhesion of a microorganism to a surface,(2) cells gathering and discrete colony formation, (3) form hyphae and secretion of extracellular polymeric substances, (4) maturation into a threedimensional structure and (5) dispersion of cells (Figure 1).

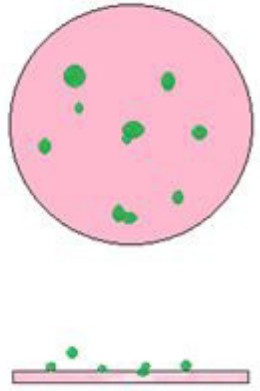

(1)
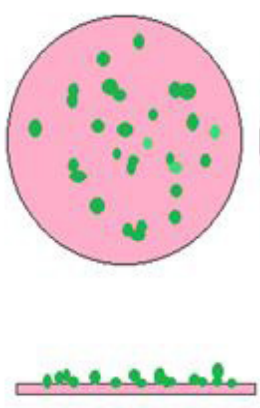

(2)
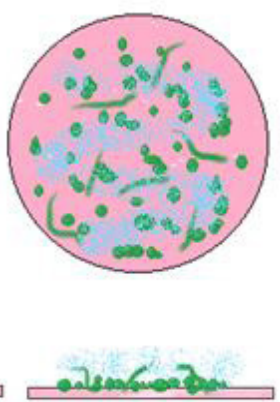

(3)

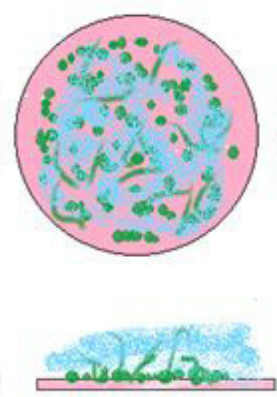

(4)
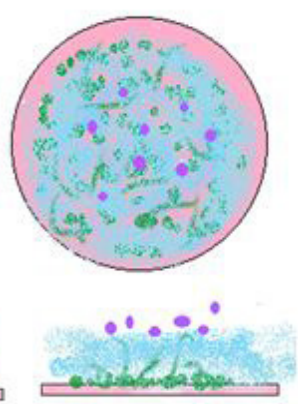

(5)

Figure 1: Stages in the formation of Candida albicans biofilm

(1) Culture medium surface with an adsorbed conditioning film of host proteins (pink). Initial yeast (green) contact the surface and adhesion to it;

(2) Formation of the basal layers of yeast micro colonies; (3) Completion of micro colony formation by addition of the upper, mainly hyphal layer. The extracellular matrix material (blue) was formed; (4) Mature biofilms contain numerous micro colonies with extracellular matrix material that surrounds both yeasts (green) and hyphae (green). They consisted of two distinct layers: a thin, basal region of densely packed yeast cells and an overlying thicker, but more open hyphal layer; (5) Mature biofilms produce new spores (purple) and disperse them

There are several reasons for the growing number of fungal infections, such as the widely using of wide-spectrum antibiotics and immunosuppressant, invasive procedures and medical implant devices. Among the fungal pathogens of humans, Candida represented by Candida albicans, is one of the species that are the most frequently associated with biofilm infection, particularly which on medical implants, and this has a significant impact on morbidity and mortality [3]. C. albicans which can cause both sup- 
erficial and systemic infections, is one of the main pathogenic microorganisms caused nosocomial infection. Data in 2002 from the US National Nosocomial Infections Surveillance System ranked C. albicans as the fourth most common cause of bloodstream infection, behind coagulase-negative staphylococci, staphylococcus aureus and enterococci, and also ranked third in cause of catheter-associated infection with a high mortality rate and high cost for treatment [4].

Biofilms display features that differ from their planktonic counterparts in morphological structure, biological and biochemical features, pathogenicity and antifungal susceptibility. Fully mature biofilms of C. albicans display high resistance to body immunity and antimicrobial agents for consisting of a dense network of yeasts, hyphae and pseudo hyphae [5]. The clinical commonly used antifungal agents are designed for microorganisms in planktonic condition, that's why Candida spp tends to display highlyresistance and refractory in biofilm form. Now biofilms have been one of the hot spots in the anti-infective study.

The availability of well-characterized, reproducible biofilm models is essential to understanding the nature of biofilms and performing studies of biofilm formation and antifungal drug resistance. C. albicans has become the main experimental fungi for studying the mechanisms of fungal biofilm formation. Considerable progress has been made in recent years in the characterization of the regulating factors and mechanisms that govern the formation and antifungal tolerance of C. albicans biofilms. A number of genes involved in all stages of biofilm formation by C. albicans, such as in adherence, matrix production, quorum sensing and especially morphogenesis, have been identified and well characterized [6-8]. Expression of these genes is under the influence of environmental conditions and regulatory pathways. All these progresses were achieved based on the development of $C$. albicans biofilms models.

This review focuses on summarizing some widely used in vitro models of C. albicans biofilms, analyzing the operating process, application and development of them, discussing the advantages and limitations of these models (Table 1). It also looks forward the research orientation in the future.

\begin{tabular}{|c|c|c|c|c|c|c|}
\hline Substrate & Type & $\begin{array}{l}\text { Suspension } \\
\text { concentra- } \\
\text { tion }\end{array}$ & $\begin{array}{l}\text { Research } \\
\text { objectives }\end{array}$ & $\begin{array}{l}\text { Intervention } \\
\text { medicine }\end{array}$ & Observation time & $\begin{array}{c}\text { Evaluation method } \\
\text { (Biofilm } \\
\text { ultrastructure/ } \\
\text { Quantitative analysis) }\end{array}$ \\
\hline \multirow{3}{*}{ Microplate } & $\begin{array}{l}\text { microplate } \\
\text { model }\end{array}$ & $1.0 \times 10^{6}$ & \multirow{2}{*}{$\begin{array}{l}\text { Antifungal } \\
\text { susceptibility } \\
\text { test }\end{array}$} & $\begin{array}{c}\text { Fluconazole, } \\
\text { amphotericin } \\
\text { B and negative } \\
\text { control }\end{array}$ & $\begin{array}{c}\mathrm{BF} \\
\text { formation:2,4,6,8,24,48h/SMICs:48h }\end{array}$ & $\begin{array}{l}\text { Light microscopy/XTT } \\
\text { assay, alamarblue }\end{array}$ \\
\hline & $\begin{array}{c}\text { Calgary biofilms } \\
\text { device }\end{array}$ & $1.0 \times 10^{7}$ & & & BF formation:2,4,6,24,36,48h & SEM/XTT assay \\
\hline & BioFlux 200 & $\mathrm{OD}_{600}$ of 0.2 & $\begin{array}{l}\text { Yeast cell } \\
\text { adherence }\end{array}$ & & After 30 minutes of flow & \\
\hline \multirow{3}{*}{ Disks } & $\begin{array}{l}\text { the Modified Robbin's } \\
\text { Device }\end{array}$ & $1.0 \times 10^{6}$ & $\begin{array}{l}\text { Structure } \\
\text { study }\end{array}$ & $\begin{array}{l}\text { Amphotericin } \\
\text { B, fluconazole }\end{array}$ & $\begin{array}{l}\text { BF formation: } 48 \mathrm{~h} \\
\text { SMICs:5, } 24 \mathrm{~h}\end{array}$ & $\mathrm{SEM} / \mathrm{XTT}$ assay \\
\hline & $\begin{array}{l}\text { Centers for disease } \\
\text { control biofilm reactor }\end{array}$ & $1.0 \times 10^{8}$ & $\begin{array}{l}\text { Structure } \\
\text { study }\end{array}$ & & $\begin{array}{c}\mathrm{BF} \\
\text { formation: } 0.5,1,6,12,24,36,48,72,96 \mathrm{~h}\end{array}$ & $\begin{array}{c}\text { CLSM/XTT,FDA,SYTO } \\
9\end{array}$ \\
\hline & $\begin{array}{l}\text { Catheter disks } \\
\text { model }\end{array}$ & $1.0 \times 10^{7}$ & $\begin{array}{l}\text { Antifungal } \\
\text { susceptibility } \\
\text { test }\end{array}$ & $\begin{array}{l}\text { Caspofungi, } \\
\text { negative } \\
\text { control }\end{array}$ & $\begin{array}{l}\text { BF formation:2,24,48h;24h } \\
\text { SMICs:26,48,72h;24-48h }\end{array}$ & $\begin{array}{l}\text { CM,CSLM,SEM/ } \\
\text { CFU,MTT,XTT,DW }\end{array}$ \\
\hline $\begin{array}{c}\text { Filter } \\
\text { membranes }\end{array}$ & $\begin{array}{l}\text { Filter membranes } \\
\text { model }\end{array}$ & $1.0 \times 10^{7}$ & $\begin{array}{l}\text { Antifungal } \\
\text { perfusion } \\
\text { study }\end{array}$ & $\begin{array}{l}\text { Amphotericin } \\
\text { B, fluconazole, } \\
\text { flucytosine }\end{array}$ & $\begin{array}{l}\text { BF formation: } 48 \mathrm{~h} \\
\text { SMICs: } 4 \mathrm{~h}\end{array}$ & $\begin{array}{l}\text { SEM/Measure the } \\
\text { growth inhibition zones }\end{array}$ \\
\hline Contact lens & $\begin{array}{l}\text { Contact lens } \\
\text { model }\end{array}$ & $1.0 \times 10^{7}$ & $\begin{array}{l}\text { Structure } \\
\text { study }\end{array}$ & & BF formation: $48 \mathrm{~h}$ & CSLM/XTT \\
\hline \multirow{2}{*}{$\begin{array}{l}\text { Petri dish } \\
\text { and glass } \\
\text { slide }\end{array}$} & $\begin{array}{l}\text { Parallel plate flow } \\
\text { chamber }\end{array}$ & & $\begin{array}{l}\text { Formation } \\
\text { mechanism } \\
\text { study }\end{array}$ & & BF formation: $48 \mathrm{~h}$ & \\
\hline & $\begin{array}{l}\text { Candida albicans } \\
\text { Biofilm Chip }\end{array}$ & $4.0 \times 10^{6}$ & $\begin{array}{l}\text { Metabolism } \\
\text { study, suscepti- } \\
\text { bility testing }\end{array}$ & $\begin{array}{l}\text { Amphotericin } \\
\text { B, fluconazole }\end{array}$ & BF formation: $24 \mathrm{~h}$ & CSLM/XTT \\
\hline
\end{tabular}

Table 1: In vitro models used to study Candida albicans biofilms

\section{In vitro models of C. albicans biofilm}

According to the culture substrate, the commonly used in vitro models mainly consist of five types: microplates model, disks model, filter membranes model, contact lens model and petri dish and glass slide model (Figure 2). Microplates model is one of the most widely used models to study the antifungal susceptibility testing of sessile organisms. It is fast, efficient, reliable, and reproducible, with high throughput potential. Disks model uses catheter disks as the culture substrate, which should be helpful for the study of medical device-associated infection. The filter membranes model uses to study the permeability of biofilms, making it 
a powerful tool in investigating the mechanism of drug resistance of biofilms. Taking human environmental conditions into consideration, the model of Centers for Disease Control biofilm reactor (CDC reactor) and Parallel Plate Flow Chamber were developed. These two kinds of in vitro models can simulate the blood continuous flow conditions, making it possible to study the interaction of biofilms and host organism.

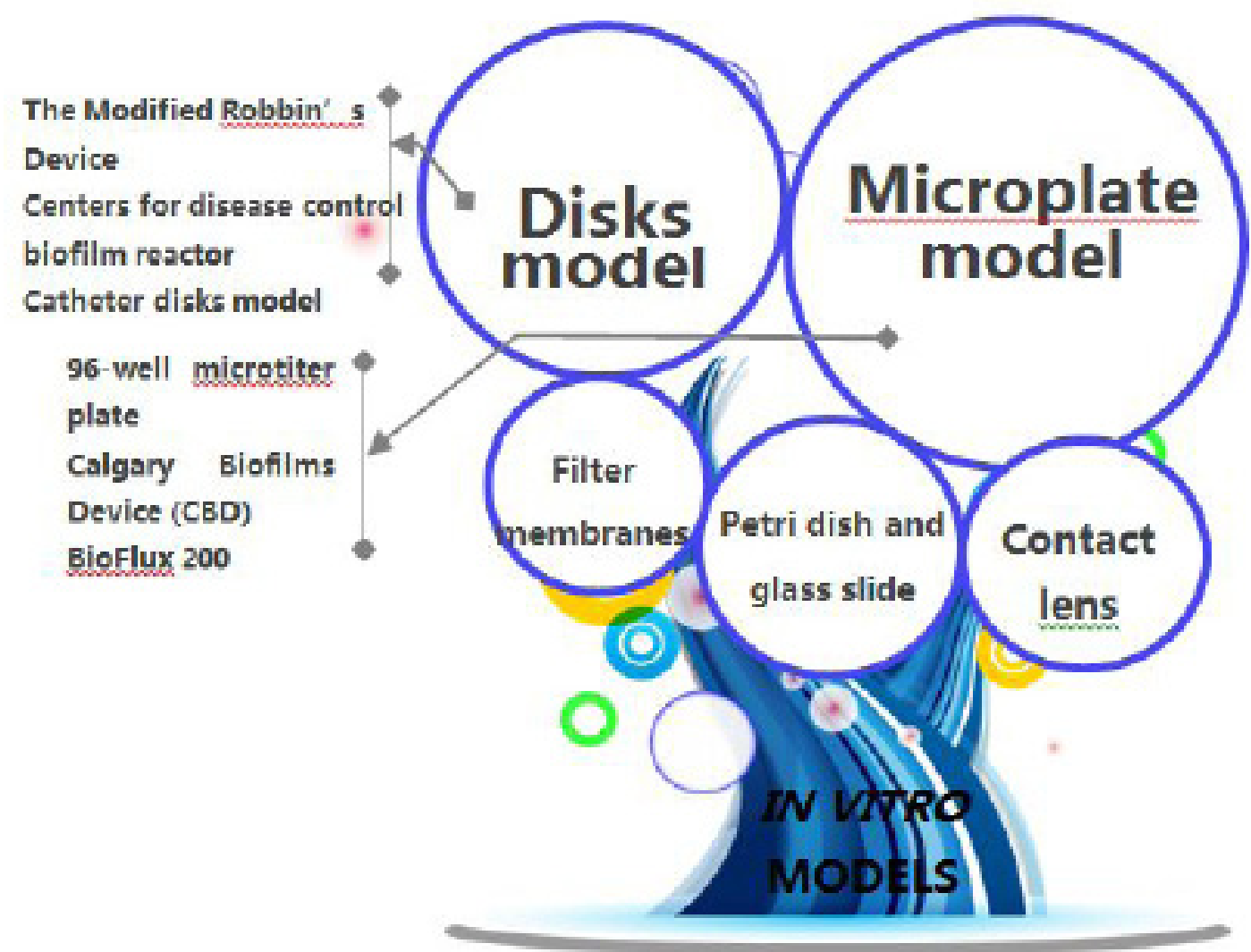

Figure 2: A review map of in vitro models of Candida albicans biofilms. The circular area represented the popularity of the model

\section{Microtiter plate model}

96-well microtiter plate model: Considering the widespread increased antimicrobial resistance and increased using of medical devices, it is crucial to establish standard methodologies that make it possible to evaluate the current and new antifungal agents against cells in biofilms. So Ramage et al [9] created a standardized method to establish a 96-well microplate in vitro model to study C. albicans biofilms in 2001 .

In this method, the C. albicans strains were propagated in yeast peptone dextrose (YPD) medium. A loopful of cells from the YPD medium were inoculated in the flasks containing liquid medium, then incubated overnight in a shaker $(100 \mathrm{rpm})$ at $30{ }^{\circ} \mathrm{C}$. Cells were harvested and resuspended in RPMI1640. The cellular density was adjusted to $1.0 \times 10^{6}$ cells per $\mathrm{ml}$ and $100 \mu \mathrm{l}$ of the standardized cell suspensions was pipeted into selected wells of the presterilized, polystyrene, flat-bottom microtiter plate and incubated at $37^{\circ} \mathrm{C}$.

Biofilms were formed over a series of time intervals $(2,4,6,8,24$ and $48 \mathrm{~h})$. At each time interval,biofilm formation was measured with the XTT-reduction assay and concurrently assessed by light microscopy. Before the measurement, the biofilms were thoroughly washing with sterile PBS three times to remove the nonadherent cells. XTT was prepared in a saturated solution at $0.5 \mathrm{~g} /$ liter in Ringer's lactate. The solution was filter sterilized through a $0.22-\mu \mathrm{m}$-pore-size filter, then stored at $37{ }^{\circ} \mathrm{C}$. Prior to each assay, an aliquot of stock XTT was thawed, and menadione (10 mM prepared in acetone) was added to a final concentration of $1 \mathrm{mM}$. A 100 $\mu \mathrm{l}$ aliquot of the XTT-menadione solution was then added to each prewashed biofilm. The solution was also added to the control wells for the measurement of background XTT-reduction levels. The plates were then incubated in the dark for up to $2 \mathrm{~h}$ at $37{ }^{\circ} \mathrm{C}$. A colorimetric change in the XTT-reduction assay, a direct correlation of the metabolic activity of the biofilm, was then measured in a microtiter plate reader at $490 \mathrm{~nm}$.

Light microscopy observations demonstrated the forming process of the biofilm. It began with small microcolonies comprised mainly of yeast cells at $2 \mathrm{~h}$. After 2 to $4 \mathrm{~h}$, the yeast cells budded and started to form pseudohypha and eventually true hyphae. At $8 \mathrm{~h}$, microcolonies then merged into an intricate network of spatially dispersed filamentous forms that intertwined to form a coherent woven-like structure (24 to $48 \mathrm{~h}$ ), with yeast cells forming aggregates along the hyphae.

The growth curve illustrated based on colorimetric reading obtained by the XTT-reduction assay reveal the metabolic activity of C. albicans biofilms. According to the growth curve, the metabolic activity of the biofilms reached a plateau in $24 \mathrm{~h}$ to $48 \mathrm{~h}$. So the 
biofilm cultivated for $24 \mathrm{~h}$ was regarded as in the mature form, which reducing greatly the experimental circle. The growth curve and the images of microscopy showed that the XTT assay absorbance readings were proportional to the cellular density of the biofilm.

This model is rapid and reproducible, and allows the testing of multiple factors within a single trial (different antimicrobials, biofilm ages, growth media, etc.). By this method, it was possible to estimate the sessile MICs (SMICs) for the biofilm organisms from the absorbance readings determined by the microtiter plate reader [10-12]. Because of its compatibility with microtiter platform and high throughput potential, it should prove to be important in the standardization of in vitro antifungal susceptibility testing of fungal biofilms, both as a research tool and in the clinical laboratory. However, they are closed systems and the conditions in which biofilms are formed are usually very different from the in vivo situation.

It's also worth noting that while the XTT formazan product readily appears in solution, there can be in some strains a significant amount of retained intracellular product, which only becomes soluble after cell treatment with DMSO. The amount of retained product may vary between different cellular states, e.g. planktonic and biofilm [13].

Calgary Biofilms Device: On the basis of standardized method mentioned above, a technology company in Canada developed Calgary Biofilms Device (CBD) [14]. It is originally designed as a test surrogate for indwelling medical devices for assessing the efficacy of antimicrobials. The major advantages offered by the CBD are its multiple equivalent biofilms that can be used for testing and its ease of use.

The CBD consists of a two-part reaction vessel. The top component forms a lid that has 96 pegs and that is sealed on the top so that the pegs can be removed without opening the vessel and allowing possible contamination. The pegs are designed to sit in the channels of the bottom component of the reaction vessel and to fit into the wells of a standard 96-well plate. The bottom of the vessel serves to channel the flow of medium across the pegs to create consistent shear force across all pegs, resulting in the formation of equivalent biofilms at each peg site (Figure 3). The CBD is commercially available as the MBEC Assay System and MIC Assay System. The minimal biofilm eradication concentration (MBEC) was defined as the minimal concentration of antibiotic required to eradicate the biofilm. The MIC in CBD was defined as the lowest concentration of antibiotic in which a planktonic microbial population could not be established by shedding of microorganism from the biofilm.

In Parahitiyawa et al's study, they reported the standardization of the CBD for C. albicans biofilm formation [15]. All test strains were cultured in Sabouraud dextrose agar plates (SDA) at $37^{\circ} \mathrm{C}$ for $18 \mathrm{~h}$. Then, a loopful of the yeasts was inoculated into yeast nitrogen base (YNB) medium supplemented with $50 \mathrm{mM}$ glucose. After overnight broth culture, the yeasts were harvested, washed twice with $5 \mathrm{ml}$ of phosphate-buffered saline (PBS; pH 7.2), centrifuged at 5,000 rpm for 5 min, resuspended in YNB growth medium supplemented with $100 \mathrm{mM}$ glucose, and standardized to $107 \mathrm{CFU} / \mathrm{mL}$ (colony-forming units). This suspension was used throughout all the experiments.

In order to develop biofilms of C. albicans on the pegs, $200 \mu \mathrm{l}$ of the standardized cell suspension (CFU/mL in YNB/100 mM glucose solution) was pipetted into each of 80 wells and $200 \mu \mathrm{l}$ of PBS into the remaining 16 wells (two controls). Then the whole $\mathrm{CBD}$ assembly was placed in a rotary incubator at $37^{\circ} \mathrm{C}$ for $180 \mathrm{~min}$ for the initial adhesion phase. The lid plate with pegs (after washing the pegs by immersing in $200 \mu \mathrm{PBS}$ aliquoted into another standard 96-well microtitre plate) was then immersed in fresh $\mathrm{YNB} / 100 \mathrm{mM}$ glucose solution and incubated for $48 \mathrm{~h}$ at $37^{\circ} \mathrm{C}$ in an aerobic incubator $(75 \mathrm{rpm})$. A series of $C$. albicans -free wells were also included to serve as controls. The metabolic activity of the 80 C. albicans biofilms established on pegs was quantified by the XTT-reduction assay.

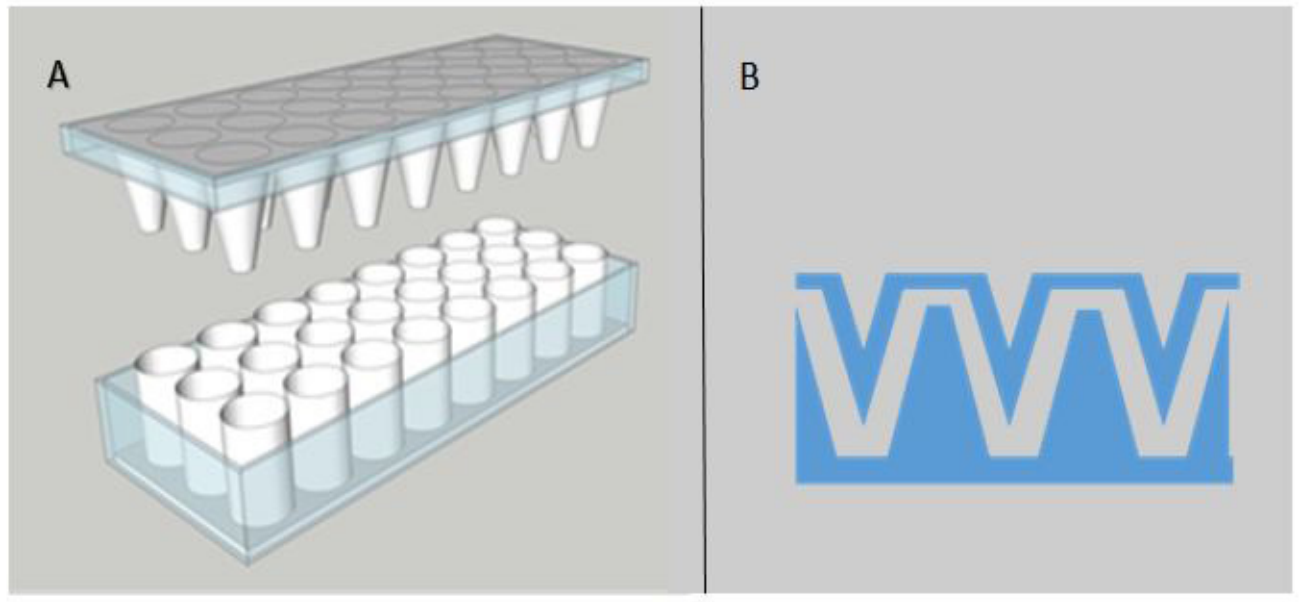

Figure 3: Schematic diagram of the CBD

(A) The CBD has two components. The top component is a lid with pegs and the bottom component is a standard 96-well plate; (B) Cutaway view of device showing that the two components can match perfectly to create a closed space, which avoids the external contamination 
The fact that the CBD requires no pumps or tubing and is devoid of complex flow systems, making the process much simpler to set up, and eliminates the major source of possible contamination. The availability of multiple testing sites greatly reduced the time required to determine the antibiotic susceptibilities of biofilms from weeks to 3 days. The CBD is also amenable to automation. The major advantage of the CBD is that it can form equivalent biofilms in the same batch. Through the use of this model, one batch

culture apparatus enable single or multiple species biofilms to be tested against an $8 \times 12$ matrix of controlled variables. These variables may include growth medium formulations, exposure times, temperature, $\mathrm{pH}$, as well as antimicrobials at varying concentrations - alone or in combination $[16,17]$. These advantages validate the CBD as a potential tool for the study of biofilm structure-function relationships.

BioFlux 200 model: The BioFlux 200 (Fluxion Biosciences) is a flow apparatus with micron scale fluidic channels that allows visualization of adherent cells with controlled flow rates. BioFlux utilizes the innovative well Plate Microfluidic technology to embed micron-scale fluidic channels on the bottom of a standard well plate. By controlling the flow across the experimental channel, you can simulate a wide range of physiological conditions. Bringing physiological flow to live cell assays allows studying the original cellular behavior in the fields of vascular biology, platelets and cardiovascular disorders, oncology, stem cells and biofilms. Some research uses this apparatus to study yeast cell adherence $[18,19]$.

In Finkel et al's study [19], $500 \mathrm{ml}$ of strains suspensions was added to each lane and each sample was run in duplicate. For each plate a reference strain was run, which later was used for fold comparison to the mutant. After loading, a flow rate of $3 \mathrm{dyne} / \mathrm{cm}^{3}$ was applied for 30 minutes at $30^{\circ} \mathrm{C}$. After 30 minutes of flow each lane had two images taken at different sites along the channel. Images were always taken at the same location in each channel for each sample. Strains with filamentous or clumping cells were not assayable. For each image the number of yeast cells adhering to the channel was tabulated. Since two pictures were taken per lane the sum of each lane was used as a single determinate and each strain thus had two trials. The average was taken for each strain and the fold change calculated (number of yeast cells adhered in the mutant strain/ number of yeast cells adhered in the reference strain).

As a flow apparatus to study cell adherence, BioFlux 200 has features such as: (1) The Pressure Interface mounts on top of the BioFlux Plates and sits on an inverted microscope. (2) The BioFlux Controller connects to the Pressure Interface and controls shear flow, temperature and flow direction. (3) BioFlux Plates are SBS-standard well plates with integrated flow cells that can be loaded using pipettes or liquid handling workstations. The bottom of each flow cell is formed with an $180 \mu \mathrm{m}$ cover slip for optimal imaging. (4) BioFlux Software offers complete control over experimental conditions, including dynamic control over shear flow changes.

Other kinds of microplate model: There are plenty of other kinds of microplates that are used to build biofilms model [20-23]. In Michael.D.LaFleur's study [24], C. albicans biofilms were grown in 384-well plates containing RPMI 1640 and were measured using the metabolic indicator alamarBlue. This assay was used to test the effect of compounds that enhanced the activity of clotrimazole or acted on the biofilms alone.

\section{Disks model}

Catheter disks model: There are several kinds of medical devices being related to fungal biofilm infection, such as urinary catheter, endotracheal tubes and central venous catheters (CVCs). Among them, CVCs are the most frequent source of nosocomial bloodstream infection which is associated with high mortality and morbidity [25]. Among CVCs-related infections, those due to Candida species are associated with an attributable mortality approaching 40\% [26,27]. Many CVCs in vitro models utilized take the catheter disks as the biofilm substrate. The models have been used to examine drug susceptibility and explore pathogenetic mechanism.

Nett et al [28]created an assay to differentiate biofilm and nonbiofilm infections in patients based on a previous finding that the concentration of $\beta-1,3$ glucan increased greatly in the cell wall of Candida biofilm cells compared with that in planktonic cells $[29,30]$. In the study, the flat, sterile medical-grade silicone disks were coated with mouse serum and incubated at $37{ }^{\circ} \mathrm{C}$ for 30 min. C. albicans was grown in YPD at $37^{\circ} \mathrm{C}$ on an orbital shaker to late logarithmic phase. After the conditioning period, $150 \mathrm{~mL}$ of culture $\left(10^{6}\right.$ cells $\left./ \mathrm{mL}\right)$ was inoculated on the disk and spread evenly. The disks were then incubated with $1 \mathrm{~mL}$ of RPMI/MOPS for $45 \mathrm{~min}$ at $37^{\circ} \mathrm{C}$. After the adherence period, disks were rinsed in sterile water and then placed in $10 \mathrm{~mL}$ of RPMI/MOPS and incubated at $37^{\circ} \mathrm{C}$ with gentle shaking for varying periods of time. Culture supernatants were collected at 4, 8, and $12 \mathrm{~h}$. The cultures were centrifuged at $3000 \mathrm{~g}$ for $20 \mathrm{~min}$, and the cell free supernatant (confirmed by light microscopy) was removed and stored at $-20^{\circ} \mathrm{C}$ until glucan analysis. Glucan concentration was determined using a limulus lysate assay, the Glucatell $(1,3)-\beta-\mathrm{d}-$ Glucan Detection Reagent Kit (Associates of Cape Cod), in accordance with the manufacturer's directions. Biofilm formation was confirmed by visual inspection and by confocal microscopy.

To study the anti-metabolic activity of caspofungi against C. albicans biofilms, Cocuanud et al [31] used a silicone disks in vitro model. Catheters in silicone were autoclaved, incubated overnight in fetal bovine serum (FBS) and washed twice with YNB-glu prior to use to produce biofilms. The sections of silicone catheters were incubated in 96-well tissue culture plates for $1 \mathrm{~h}$ at $37{ }^{\circ} \mathrm{C}$ with $200 \mu \mathrm{L}$ of a suspension of C. albicans $\left(5 \times 10^{6}\right.$ blastospores $\left./ \mathrm{mL}\right)$. Each section was then washed twice with YNB-glu to remove the non-adherent yeasts, moved into a new well of the culture plate, and incubated for 2, 24 or $48 \mathrm{~h}$ in YNB-glu to obtain biofilms with different maturation stages. Each section of catheter coated with Candida biofilm of 2, 24 or 48 h of maturation was incubated 
in a new well of the culture plate for $24 \mathrm{~h}$ at $37^{\circ} \mathrm{C}$ with YNB-glu+ caspofungin used at two concentrations: A low concentration corresponding to the MIC for each tested strain and a therapeutic concentration of $2 \mathrm{mg} / \mathrm{L}$. Controls without antifungal were included in each experiment. The metabolic activity was assessed using the XTT assay.

Besides two models above, some studies established C. albicans biofilms models with catheter disks in 24-well tissue culture plates, 12 -well plates or 6-well plates [5,32-34]. The measurement of biofilms included XTT assay, dry weight measuring, CFU and so forth $[5,35]$.

The modified Robbin's Device (MRD): The MRD is one of the most widely used systems for studying biofilm growth under conditions of continuous flow. It can be used both in bacteria and fungi. The MRD can be used in studying biofilm physiology and antibiotic susceptibility [3,36]. It is an artificial multiport sampling catheter, constructed of a perspex block, $41.5 \mathrm{~cm}$ long, with a rectangular lumen containing 25 evenly spaced sample ports [37]. The sample studs, also made of Perspex, fit tightly into the ports. Each stud has at its bottom end a $1 \mathrm{~mm}$ rim into which a catheter disk can be inserted (Figure 4). During incubation, biofilms are formed on these disks and can be removed aseptically by simply taking out the sample study.

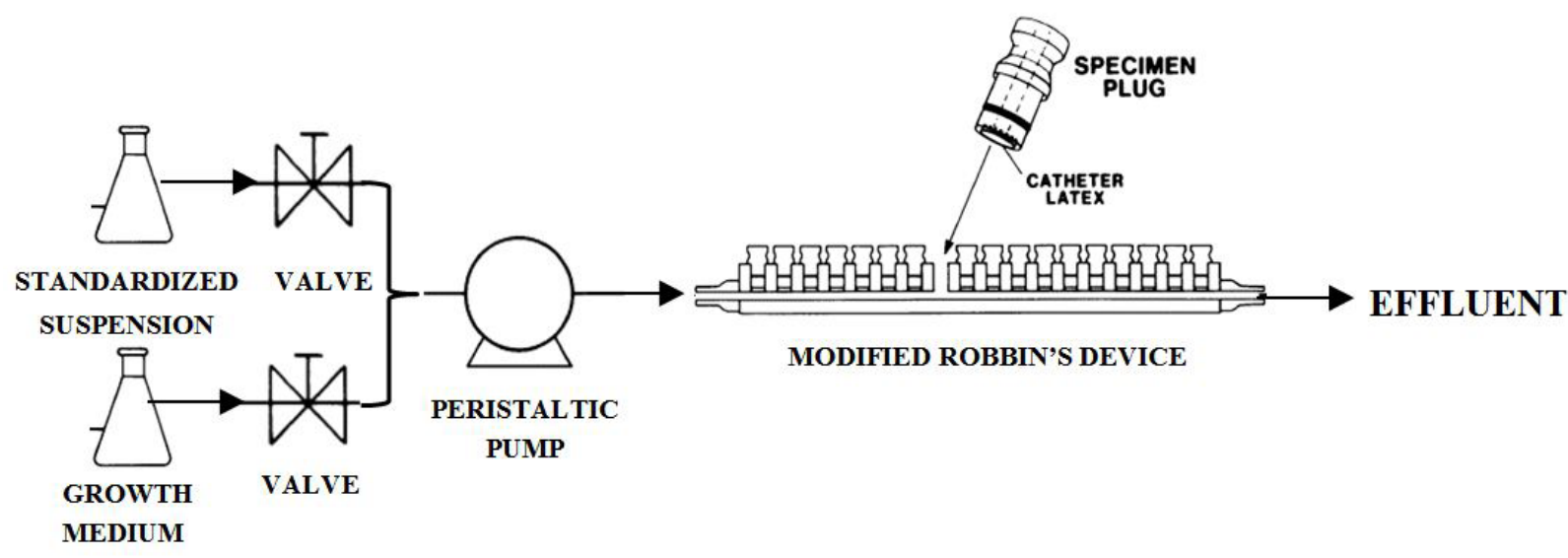

Figure 4: Diagrammatic representation of the modified Robbins device and the apparatus used to provide a flow of growth medium and cell suspension

In Al-Fattani et al [37]'s study, they used the MRD to study the characterization of biofilms which were grown underflow conditions. In short, a reservoir containing a standardized suspension of the test organism (s) was connected to a peristaltic pump and the $\mathrm{MRD}$ via silicone tubing. The entire apparatus was incubated at $37^{\circ} \mathrm{C}$. Cell suspension was pumped through the MRD at a flow rate of $60 \mathrm{ml} / \mathrm{h}$ for $1 \mathrm{~h}$ to allow cells to adhere to each of the 25 catheter disks attached to the sample studs. Upon leaving the MRD, the cell suspension was collected in an effluent container. Fresh growth medium was then continuously pumped through the MRD at the same flow rate for $48 \mathrm{~h}$. After this time, biofilms formed on the catheter disks could be retrieved by removing the sample studs from the MRD.

Scanning electron microscope (SEM) showed that biofilms grown in the MRD under flow conditions had an extensive matrix which confirmed the earlier findings that biofilms subjected to a liquid flow produce substantially more matrix material than those incubated statically.

Previous study showed that the biofilms grown with or without shaking did not exhibit significant differences in susceptibility to some common antifungal agents [29]. While in Al-Fattani et al [37]'s study, C. albicans biofilms grown under flow conditions were significantly more resistant than those grown statically. A possible explanation for this contradiction is that the shaking procedure, which produced conditions of turbulent flow, was less effective at stimulating matrix synthesis than the laminar flow system provided by the MRD. So the MRD is more suitable for simulating in vivo conditions.

Centers for Disease Control biofilm reactor: It has been shown that some particular genes are important for C. albicans biofilm formation and the expression of these genes is influenced by the growth medium and other environmental conditions [38,39]. As such it can be anticipated that the biofilm model system can have a considerable impact on the growth of biofilms, as some systems do not incorporate fluid flow (e.g., biofilm formation in a microtiterplate). Other systems do incorporate this aspect, but the medium is not replaced (e.g., biofilm formation in microtiter plates on a rocking table). Compared with the models described above, The Centers for Disease Control biofilm reactor (CDC reactor) allows the continuous replacement of growth medium while subjecting the biofilms to a continuous flow. It has been used to study biofilm formation of various bacterial (e.g., Streptococcus pneumoniae) and fungal (e.g., C. albicans) pathogens [40-42].

The CDC reactor consists of a $1 \mathrm{~L}$ jacketed vessel with an effluent spout connected to a waste bottle. The jacket has two ports, which are connected to a circulating water bath set at $37^{\circ} \mathrm{C}$. The lid of the vessel contains eight independent rods, each holding three silicone disks and three stainless steel ports allowing growth medium to be continuously pumped through the reactor vessel. Disks could be removed from the reactor at desired time intervals by withdrawing the disks holder through the lid of the reactor [40]. 
Nailis et al [43] determined the relative expression of ALS1 and ALS3 (two genes which were related to biofilms formation) during biofilm formation in the CDC reactor using Reverse Transcriptase-quantitative PCR (RT-qPCR). The components of the experiment system were showed in Figure 5. In brief, cells were incubated in Sabouraud Dextrose Broth (SDB) (BD) for 16 h at $37^{\circ} \mathrm{C}$ in a shaking water bath. After incubation, cells were washed three times with and finally resuspended in $1 \mathrm{ml}$ of $0.9 \%$ (w/v) $\mathrm{NaCl}$ and further used to grow biofilms. Cells were added to $500 \mathrm{ml}$ growth medium (19 YNB, $50 \mathrm{mM}$ glucose), transferred to the reactor vessel, and stirred at $80 \mathrm{rpm}$. After $24 \mathrm{~h}$ of biofilm formation, diluted growth medium (0.29 YNB, $10 \mathrm{mM}$ glucose) was continuously pumped through the reactor at a flow rate of $400 \mathrm{ml} / \mathrm{h}$. In several time points of biofilm formation, silicone disks were taken out of the reactor vessel and transferred to 24-well microtiter plates for further observation.

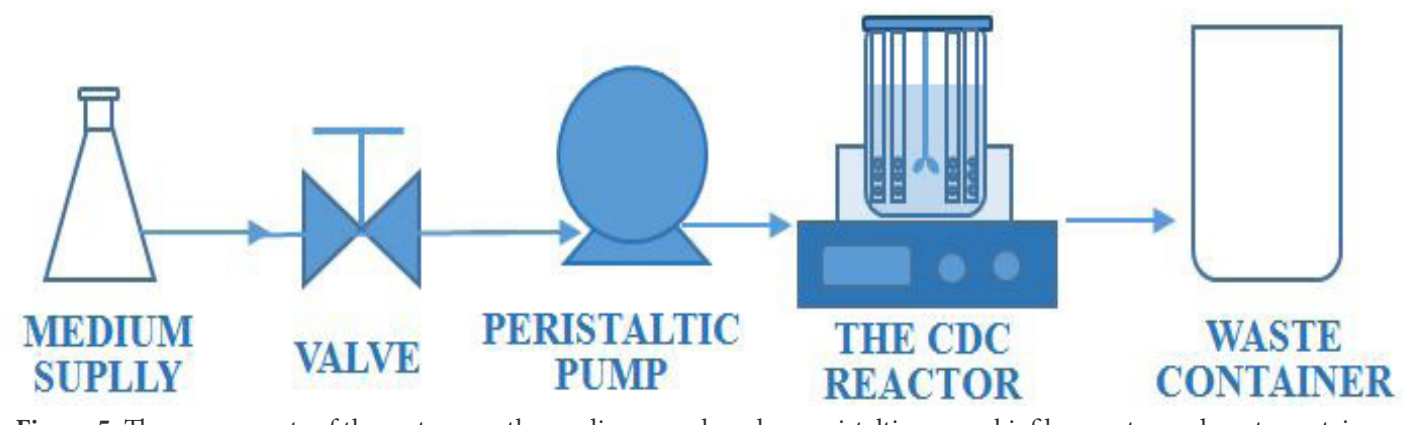

Figure 5: The components of the system are the medium supply, valve, peristaltic pump, biofilm reactor and waste container

The use of the CDC reactor allowed the formation of high-density C. albicans biofilms on silicone disks under continuous flow conditions with constant medium replacement. With different measuring components, the biofilm reactor is suited for detecting the protein, polysaccharide of biofilms and for measuring biofilm formation continuously over time.

Advantages and limitations of MRD and CDC: There two model systems have a lower throughput, are more labour-intensive and require specialized equipment and technical skills. In addition, they often require larger volumes of media and other reagents. While these systems have the advantage of incorporating the important aspect of fluid flow in the setup, other aspects encountered in the in vivo situation such as immunological factors and symbiotic micro flora are missing. In the systems, biofilms are formed on multiple coupons in the same reactor vessel and as a consequence only a single organism (or a single community) can be tested per run. The same is true for the treatments in the reactor vessel: only treatment with a single product or a single combination of products is possible and only a single type of modified material can be tested per run.

\section{Petri dish and glass slide models}

Parallel plate flow chamber: Adhesion between C. albicans cells and materials or host cells has been implicated as an early step in biofilm formation. By using the parallel plate flow chamber, Li et al [44] simulates the real situation of vessels in human being to identify C. albicans genes that induce adhesion.

The parallel plate flow chamber consists of a flow deck that fits inside a 60-mm Petri dish. A silicone rubber gasket (width $=0.25$ $\mathrm{cm}$, thickness $=0.01 \mathrm{in}$.) is placed between the flow deck and the $60-\mathrm{mm}$ Petri dish to form the flow chamber. The Petri dish was attached to the flow deck and the gasket by holding the deck inverted and vacuum was applied to hold the Petri dish on the deck. A peristaltic pump connected to the inlet of the flow chamber provides relatively constant velocity flow through the chamber. The shear stress generated by the flow at the bottom surface of the flow chamber detaches yeast cells from the surface. The volumetric flow rate was varied to obtain the desired shear stress $[45,46]$.

After assembly, the flow chamber was placed on a motorized X-Y stage (Prior) of an Olympus IX70 inverted microscope. Three fields were selected under the microscope and the positions were memorized by the motorized stage.

C. albicans cells were cultured overnight at $30^{\circ} \mathrm{C}$ in YPD medium. Cells were pelleted and resuspended in $0.1 \mathrm{M}$ sodium phosphate buffer ( $\mathrm{pH}$ 6.0). The suspension was injected into the flow chamber, which was placed on the stage of a microscope enclosed in a 37 ${ }^{\circ} \mathrm{C}$ constant-temperature box. Following a $30 \mathrm{~min}$ incubation to allow the cells to adhere to the surface of a polystyrene petri dish, the flow of sterile YPD medium was induced at a shear stress of 6 dyne $/ \mathrm{cm}^{2}$. Images of several fields of the flow chamber surface were acquired to capture the growth of cells on the surface as time progressed.

The parallel plate flow chamber model can simulate the shear stress created by blood flow, which make it possible to investigate the role of adhesion-related genes of C. albicans in the process of biofilms formation.

High-throughput nano-biofilm microarray- $\mathrm{CaBChip}$ : In order to satisfy the demand for highthroughput screening of thousands of molecules for new drugs against fungal infection, Srinivasan et al have developed a high-density microarray platform consisting of nano- biofilms of Candida albicans [47]. The C. albicans biofilm chip (CaBChip) is composed of 768 equivalent and spatially distinct nano-biofilms on a single standard 1 " $\times 3$ " glass slide. Multiple chips can be printed and processed simultaneously. By using $\mathrm{CaBChip}$, Srinivasan et al assessed the metabolic status of cells within biofilms and performed susceptibility testing of cells within C. albicans biofilms against clinically used antifungal agents and a collection of known pharmacologically active small compounds [48-51]. 
Compared to current methods for the formation of microbial biofilms, namely the 96-well microtiter plate model, this fungal biofilm chip has advantages in terms of miniaturization and automation, which combine to cut reagent use and analysis time, minimize labor intensive steps, and dramatically reduce assay costs. Such a chip should accelerate the antifungal drug discovery process by enabling rapid, convenient and inexpensive screening of hundreds-to thousands of compounds simultaneously.

\section{Filter membranes model}

Once the biofilm mode of growth is established in human body, the sessile yeasts begin to display unique characteristics of resistance to antifungal agents. The low diffusion gradient of the antimicrobial through the extracellular polymer matrix of the biofilm is one of the factors thought to contribute to the resistance in Candida biofilms. So Samaranayake et al [52] used a modified filter membranes model to investigated the perfusion of three kinds of commonly used antifungal agents in biofilms of $C$. albicans.

This model was a modification of a method described by Jeff $\mathrm{N}$ Anderl [28]. A schematic presentation of this model is shown in Figure 6. In brief, biofilms were developed on Isopore membrane filters (diameter, $25 \mathrm{~mm}$; pore size, 12 $\mu \mathrm{m}$; Millipore). The filter membranes were sterilized by exposure to UV light (15 min per side), and each membrane was aseptically placed on a Sabouraud's dextrose agar (500 mM galactose) plate. Afterwards, $50 \mu \mathrm{l}$ of an overnight Candida inoculum ( $\left.10^{7} \mathrm{CFU} / \mathrm{ml}\right)$ was carefully deposited on the membrane with a pipette. The nutrient agar plates with the inoculum were incubated at $37^{\circ} \mathrm{C}$ for $1 \mathrm{~h}$ (to dry the deposit), and then the plate was inverted and reincubated at $37^{\circ} \mathrm{C}$ for a period of $48 \mathrm{~h}$. During this incubation period, each filter with the growing biofilm was manually lifted and repositioned on a fresh location on the plate every 10 to $12 \mathrm{~h}$.

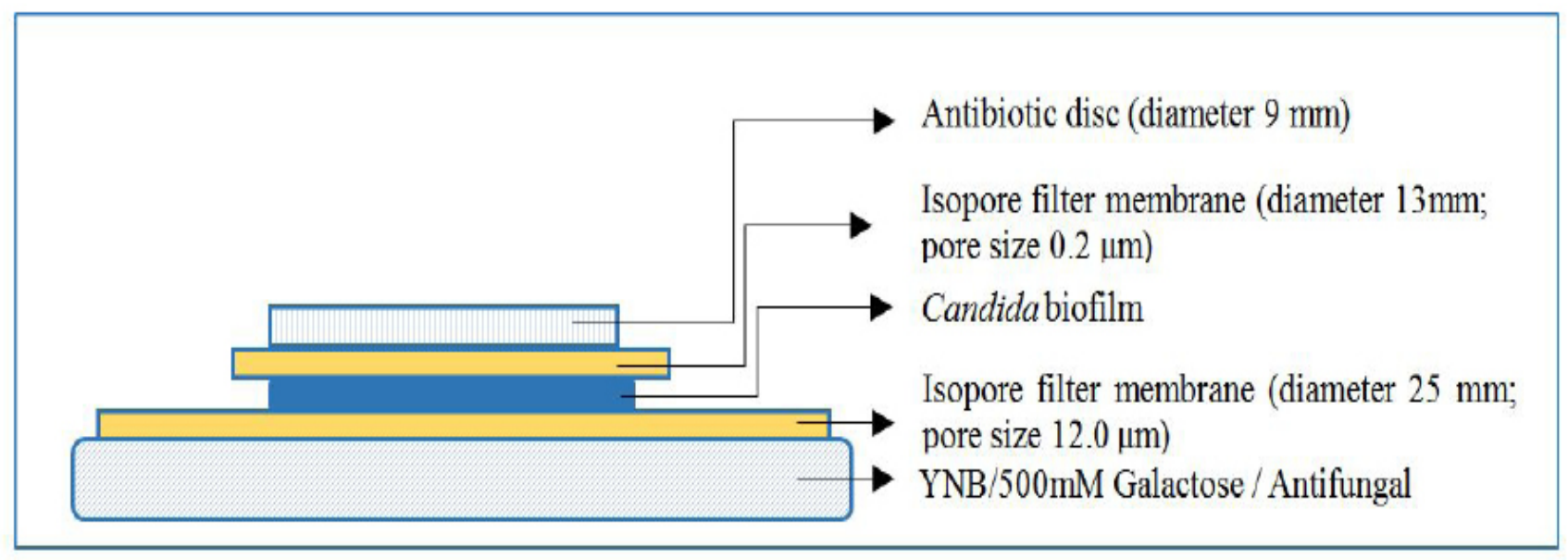

Figure 6: A schematic presentation of the model used to investigate the penetration of antifungal through Candida biofilms: The biofilm was developed on a 25-mm-diameter microporous polycarbonate membrane resting on the agar medium. A 13 -mm-diameter microporous polycarbonate membrane was placed on top of the biofilm, and then a moistened blank antibiotic disk was placed on top of the polycarbonate membrane. The entire unit (four layers above) was then transferred to antifungal-laced agar

After $48 \mathrm{~h}$, the biofilms on the membrane filters were placed on an antibiotic incorporated agar medium prepared as described above with the biofilm facing outwards. Black microporous membrane filters (diameter, $13 \mathrm{~mm}$; pore size, $0.2 \mu \mathrm{m}$; Millipore) were then placed on top of 48-h-old Candida biofilms. A blank antibiotic (AB) disk (diameter, $9 \mathrm{~mm}$; Difco) moistened with 10 $\mu$ of PBS (pH 7.2) was then placed on top of the 13-mm-diameter membrane (wetting the disk obviates passive capillary perfusion of the antifungal through the biofilm). The whole assembly was then incubated at $37^{\circ} \mathrm{C}$ for $4 \mathrm{~h}$. A semi quantitative evaluation of the antifungals that diffused into an $\mathrm{AB}$ disk through the biofilm was performed.

SEM showed that the C. albicans developed satisfactory biofilms on membrane filters, and the whole assembly could be easily detached from the substrate surface for the diffusion studies. The use of the AB disk with the antifungal and the antifungal sensitivity assay with C. parapsilosis as the indicator organism yielded reproducible results on repeat experiments conducted on separate occasions, indicating satisfactory sensitivity of the assay system. The model appears to be simple and versatile for the study of differential perfusion of antifungals or other solutes through the biofilms of various Candida species.

\section{Contact lens model}

Fungal keratitis is a devastating ocular disease which may account for more than $50 \%$ of all ocular mycoses, and it has been reported in different parts of the world [53-55]. It is commonly caused by Fusarium species and Candida species [56]. A retrospective review of fungal keratitis cases at the University of Florida form 1999 to 2006 [57] showed that, after 2005, contact lens use has been the first risk factor of this disease (52\%), ahead of trauma(29\%) and prior application of corticosteroids [58]. One mechanism by which fungal keratitis exhibits a drug-resistant phenotype may be formation of biofilms.

To characterize biofilms formed by C. albicans on soft contact lens, Imamura et al [59] established an in vitro model of contact lens-associated Candida biofilms. Furthermore, they used this model to determine the susceptibility of Candida biofilms to two kinds of contact lens care solutions. 
C. albicans was grown overnight at $37^{\circ} \mathrm{C}$ in yeast nitrogen base medium (YNB) supplemented with 50 mM glucose. Candida cells were harvested, washed with PBS, and standardized to 107 blastospores/ml for biofilm formation experiments. Soft contact lenses were washed with PBS, placed in 12-well tissue culture plates with $4 \mathrm{ml}$ standardized cell suspension, and incubated for 90 min at $37^{\circ} \mathrm{C}$ (adherence phase). Nonadherent cells were removed from soft contact lenses by gentle washing with $4 \mathrm{ml}$ PBS. Next, soft contact lenses were immersed in YNB and incubated for $48 \mathrm{~h}$ at $37^{\circ} \mathrm{C}$ on a rocker. Biofilms were quantified using a tetrazolium XTT assay. Planktonic cells were grown in 12-well plates in the absence of a contact lens.

The architecture of biofilms formed on soft contact lenses was analyzed using confocal scanning laser microscopy (CSLM). A digital camera was used to capture images of the biofilms to compare their gross morphologies and appearances. The results showed that $C$. albicans can form biofilms on the different lens types tested. The architecture of C. albicans biofilms formed on contact lenses is heterogeneous and dependent on lens surface properties.

The in vitro model developed for lens-associated fungal biofilms will be helpful for better understanding the biology, pathogenesis, and antifungal resistance of Candida biofilms and their role in contact lens-related fungal keratitis. In addition, this model has utility in evaluation of lens care solutions for their antibiofilm activity.

\section{Problems Currently Encountered and Future Prospects}

The issues of superbug and hospital- required infection have been paid more and more attraction at present. The in-depth study of resistance mechanisms of fungi represented by C. albicans are continuously. Biofilms are attracted great attention currently for its significant difference with planktonic cells in drug resistance.

The advantages of in vitro model of $C$. albicans biofilms are easy to establish, shorter maturation times, low-cost, high reliability and fine repetition. So over the past decades, in vitro model has been greatly developed. There are many types of in vitro model established in different medium surfaces and devices, the most suitable one being dependent on the information being sought. It is notable that each model has its limitation. Take MRD as example, while this is a well-recognized model, it requires expert handling,

relatively few equivalent biofilms can be produced, requires longer processing times, and is more open to contamination. Membrane-associated biofilm models are not amenable to high-throughput screening. Microtiter plate model is the most widely used tools for biofilm study, but the system doesn't incorporate fluid flow and the medium is not replaced.

Through the validation of in vitro findings, the formation process, related genes and proteins of C. albicans biofilms are better understood. However, the key limitation of in vitro models is that they can only study biofilms in isolation, but not take interactions into consideration. The interactions include which between biofilms and the immune system of host organism, as well as the interaction of different kinds of microorganisms in human body. This limitation of in vitro models underscores a need for in vivo models to study such issues. The appropriate in vivo models can provide a realistic condition of infection site, blood flow, host conditioning protein and the host immunity-biofilm interaction. Unfortunately, the establishment of in vivo models is so far a field which few studies involved. To better understand and control biofilm infections, researchers must make progress in a number of key areas. Among these is the development of models to more closely simulate host environment.

Despite our progress in understanding C. albicans infection, there remains a high mortality associated with it. Exciting advances in adherence, matrix production, quorum sensing and especially morphogenesis, provide new information about the pathogenic mechanism of the Candidiasis and further our understanding of biofilms development, progression, and recurrence. Further refinement of in vitro models of $C$. albicans biofilms which including awareness of the limitations each model presents, and taking advantage of the technologies available to study these models will undoubtedly expedite the success of new treatments.

\section{Acknowledgements}

This article is supported by Science and Technology of Shandong Province (2010GWZ20217, 2013GSF11848) and Shandong Provincial Natural Science Foundation (ZR2011HL049), China.

\section{References}

1. Tobudic S, Kratzer C, Lassnigg A, Presterl E (2012) Antifungal susceptibility of Candida albicans in biofilms. Mycoses 55: 199-204.

2. Chandra J, Kuhn DM, Mukherjee PK, Hoyer LL, McCormick T, et al. (2001) Biofilm formation by the fungal pathogen Candida albicans: development, architecture, and drug resistance. J Bacteriol 183: 5385-94.

3. Kumamoto CA (2002) Candida biofilms. Curr Opin Microbiol 5: 608-11.

4. Calderone R (2002) Introduction and historical perspectives Candida and Candidiasis. ASM Press 3-13.

5. Hawser SP, Douglas LJ (1994) Biofilm formation by Candida species on the surface of catheter materials in vitro. Infect Immun 62: $915-21$.

6. García-Sánchez S, Aubert S, Iraqui I, Janbon G, Ghigo JM, et al. (2004) Candida albicans biofilms: a developmental state associated with specific and stable gene expression patterns. Eukaryot cell 3: 536-45.

7. Marchais V, Kempf M, Licznar P, Lefrançois C, Bouchara JP, et al. (2005) DNA array analysis of Candida albicans gene expression in response to adherence to polystyrene. FEMS Microbiol Lett 245: 25-32.

8. Murillo LA, Newport G, Lan CY, Habelitz S, Dungan J, et al. (2005) Genome-wide transcription profiling of the early phase of biofilm formation by Candida albicans. Eukaryot Cell 4: 1562-73. 
9. Ramage G, Walle KV, Wickes BL, Lopez-Ribot JL (2001) Standardized method for in vitro antifungal susceptibility testing of Candida albicansbiofilms. Antimicrob Agents Chemother 45: 2475-9.

10. Jacobson MJ, Steckelberg KE, Piper KE, Steckelberg JM, Patel R (2009) In vitro activity of micafungin against planktonic and sessile Candida albicans isolates. Antimicrob Agents Chemother 53: 2638-9.

11. Pierce CG, Uppuluri P, Tristan AR, Wormley FL, Mowat E, et al. (2008) A simple and reproducible 96-well plate-based method for the formation of fungal biofilms and its application to antifungal susceptibility testing. Nat protoc 3: 1494-500.

12. Shuford JA, Piper KE, Steckelberg JM, Patel R (2007) In vitro biofilm characterization and activity of antifungal agents alone and in combination against sessile and planktonic clinical Candida albicans isolates. Diagn Microbiol Infect Dis 57: 277-81.

13. Kuhn DM, Balkis M, Chandra J, Mukherjee PK, Ghannoum MA (2003) Uses and limitations of the XTT assay in studies of Candida growth and metabolism. J Clin Microbiol 41: 506-8.

14. Ceri H, Olson ME, Stremick C, Read RR, Morck D, et al. (1999) The Calgary Biofilm Device: new technology for rapid determination of antibiotic susceptibilities of bacterial biofilms. J clin microbiol 37: 1771-6.

15. Parahitiyawa NB, Samaranayake YH, Samaranayake LP, Ye J, Tsang PW, et al. (2006) Interspecies variation in Candida biofilm formation studied using the Calgary biofilm device. APMIS 114: 298-306.

16. Ali L, Khambaty F, Diachenko G (2006) Investigating the suitability of the Calgary Biofilm Device for assessing the antimicrobial efficacy of new agents. Bioresour Technol 97: 1887-93.

17. Harrison JJ, Ceri H, Yerly J, Stremick CA, Hu Y, et al. (2006) The use of microscopy and three-dimensional visualization to evaluate the structure of microbial biofilms cultivated in the Calgary Biofilm Device. Biol proced online 8: 194-215.

18. Wahab AA, Taj-Aldeen SJ, Kolecka A, ElGindi M, Finkel JS, et al. (2014) High prevalence of Candida dubliniensis in lower respiratory tract secretions from cystic fibrosis patients may be related to increased adherence properties. Int J Infect Dis 24: 14-9.

19. Finkel JS, Xu W, Huang D, Hill EM, Desai JV, et al. (2012) Portrait of Candida albicans adherence regulators. PLoS Pathog 8: e1002525.

20. Cavalcanti IM, Silva WJ, Lucena SC, Pousa CC, Del Bel Cury AA (2013) Influence of substratum position and acquired pellicle on Candida albicans biofilm. Braz Oral Res 27: 369-75.

21. Staniszewska M, Bondaryk M, Ochal Z (2015) Susceptibility of Candida albicans to new synthetic sulfone derivatives. Arch Pharm (Weinheim) $348: 132-43$.

22. Jafari AA, Falah Tafti A, Hoseiny SM, Kazemi A (2015) Antifungal Effect of Zataria multiflora Essence on Experimentally Contaminated Acryl Resin Plates With Candida albicans. Iran Red Crescent Med J 17: e16552.

23. Haghighi F, Mohammadi ShR, Mohammadi P, Eskandari M, Hosseinkhani S (2012) The titanium dioxide nanoparticles by XTT method and ATPase assay. Bratisl Lek Listy 113: 707-11.

24. LaFleur MD, Lucumi E, Napper AD, Diamond SL, Lewis K (2011) Novel high-throughput screen against Candida albicans identifies antifungal potentiators and agents effective against biofilms. J Antimicrob Chemother 66: 820-6.

25. Vergidis P, Patel R (2012) Novel Approaches to the Diagnosis, Prevention and Treatment of Medical Device-Associated Infections. Infect Dis Clin North Am 26: $173-86$.

26. Rex JH, Bennett JE, Sugar AM, Pappas PG, van der Horst CM, et al. (1994) A randomized trial comparing fluconazole with amphotericin B for the treatment of candidemia in patients without neutropenia. Candidemia Study Group and the National Institute. N Engl J Med 331: 1325-30.

27. Wey SB, Mori M, Pfaller MA, Woolson RF, Wenzel RP (1988) Hospital-acquired candidemia: the attributable mortality and excess length of stay. Arch Intern Med 148: 2642-5.

28. Nett J, Lincoln L, Marchillo K, Andes D (2007) $\beta-1,3$ glucan as a test for central venous catheter biofilm infection. J Infec Dis 195: $1705-12$.

29. Baillie GS, Douglas LJ (2000) Matrix polymers of Candida biofilms and their possible role in biofilm resistance to antifungal agents. J Antimicrob Chemother 46: 397-403.

30. Nett J, Lincoln L, Marchillo K, VanHandel M, Andes D (2000) Comparison of cell wall of biofilm and planktonic C. albicans. $8^{\text {th }}$ ASM Conference on Candida and Candidiasis (Denver). Washington, DC, American Society for Microbiology 75.

31. Cocuaud C, Rodier MH, Daniault G, Imbert C (2005) Anti-metabolic activity of caspofungin against Candida albicans and Candida parapsilosis biofilms. J Antimicrob Chemother 56: 507-12.

32. Kuhn DM, George T, Chandra J, Mukherjee PK, Ghannoum MA (2002) Antifungal susceptibility of Candida biofilms: unique efficacy of amphotericin B lipid formulations and echinocandins. Antimicrob Agents Chemother 46: 1773-80.

33. Negri M, Martins M, Henriques M, Svidzinski TI, Azeredo J, et al. (2010) Examination of potential virulence factors of Candida tropicalis clinical isolates from hospitalized patients. Mycopathologia 169: 175-82.

34. Richard ML, Nobile CJ, Bruno VM, Mitchell AP (2005) Candida albicans biofilm-defective mutants. Eukaryot Cell 4: $1493-502$.

35. Adam B, Baillie GS, Douglas LJ (2002) Mixed species biofilms of Candida albicans and Staphylococcus epidermidis. J Med Microbiol 51: 344-9.

36. Raad I, Darouiche R, Hachem R, Sacilowski M, Bodey GP (1995) Antibiotics and prevention of microbial colonization of catheters. Antimicrob Agents Chemother 39: 2397-400.

37. Al-Fattani MA, Douglas LJ (2006) Biofilm matrix of Candida albicans and Candida tropicalis: chemical composition and role in drug resistance. J Med Microbiol 55: 999-1008.

38. Nobile CJ, Andes DR, Nett JE, Smith FJ, Yue F, et al. (2006) Critical role of Bcr1-dependent adhesins in C. albicans biofilm formation in vitro and in vivo. PLoS pathogens 2: e63.

39. Zhao X, Daniels KJ, Oh SH, Green CB, Yeater KM, et al. (2006) Candida albicans Als3p is required for wild-type biofilm formation on silicone elastomer surfaces. Microbiol 152: 2287-99.

40. Donlan RM, Piede JA, Heyes CD, Sanii L, Murga R, et al. (2004) Model system for growing and quantifying Streptococcus pneumoniae biofilms in situ and in real time. Appl Environ Microbiol 70: 4980-8.

41. Honraet K, Goetghebeur E, Nelis HJ (2005) Comparison of three assays for the quantification of Candida biomass in suspension and CDC reactor grown biofilms. J Microbiol Methods 63: 287-95.

42. Nailis H, Coenye T, Van Nieuwerburgh F, Deforce D, Nelis HJ (2006) Development and evaluation of different normalization strategies for gene expression studies in Candida albicans biofilms by real-time PCR. BMC molecular biology 7: 25.

43. Nailis H, Vandenbroucke R, Tilleman K, Deforce D, Nelis H, et al. (2009) Monitoring ALS1 and ALS3 gene expression during in vitro Candida albicans biofilm formation under continuous flow conditions. Mycopathologia 167: 9-17. 
44. Li F, Svarovsky MJ, Karlsson AJ, Wagner JP, Marchillo K, et al. (2007) Eaplp, an adhesin that mediates Candida albicans biofilm formation in vitro and in vivo. Eukaryot Cell 6: 931-9.

45. Li F, Palecek SP (2003) EAP1, a Candida albicans gene involved in binding human epithelial cells. Eukaryot Cell 2: $1266-73$.

46. Li F, Palecek SP (2005) Identification of Candida albicans genes that induce Saccharomyces cerevisiae cell adhesion and morphogenesis. Biotechnol Prog 21: 1601-9.

47. Srinivasan A, Uppuluri P, Lopez-Ribot J, Ramasubramanian AK (2011) Development of a high-throughput Candida albicans biofilm chip. PLoS One 6: e19036. 48. Srinivasan A, Gupta CM, Agrawal CM, Leung KP, Lopez-Ribot JL, et al. (2014) Drug susceptibility of matrix-encapsulated Candida albicans nano-biofilms. Biotechnol Bioeng 111: 418-24.

49. Srinivasan A, Leung KP, Lopez-Ribot JL, Ramasubramanian AK (2013) High-throughput nano-biofilm microarray for antifungal drug discovery. mBio 4: e00331-13.

50. Siles SA, Srinivasan A, Pierce CG, Lopez-Ribot JL, Ramasubramanian AK (2013) High-throughput screening of a collection of known pharmacologically active small compounds for identification of Candida albicans biofilm inhibitors. Antimicrob Agents Chemother 57: $3681-7$.

51. Srinivasan A, Lopez-Ribot JL, Ramasubramanian AK (2012) Candida albicans biofilm chip (CaBChip) for high-throughput antifungal drug screening. J Vis Exp e3845.

52. Samaranayake YH, Ye J, Yau JYY, Cheung BPK, Samaranayake LP (2005) In vitro method to study antifungal perfusion in Candida biofilms. J Clin Microbio 43: 818-25.

53. Agarwal A, Gupta A, Sakhuja V, Talwar P, Joshi K, et al. (1991) Retinitis following disseminated cryptococcosis in a renal allograft recipient. Efficacy of oral fluconazole. Acta Ophthalmol (Copenh) 69: 402-5.

54. Adler DE, Milhorat TH, Miller JI (1998) Treatment of rhinocerebral mucormycosis with intravenous, interstitial, and cerebrospinal fluid administration of amphotericin B: case report. Neurosurgery 42: 644-8.

55. Agrawal V, Biswas J, Madhavan HN, Mangat G, Reddy MK, et al. (1994) Current perspectives in infectious keratitis. Indian J Ophthalmol $42: 171-92$.

56. Ajayi BG, Osuntokun B, Olurin O, Kale OO, Junaid TA (1986) Orbital histoplasmosis due to Histoplasma capsulatum var. duboisii: successful treatment with Septrin. J Trop Med Hyg 89: 179-87.

57. Iyer SA, Tuli SS, Wagoner RC (2006) Fungal keratitis: emerging trends and treatment outcomes. Eye contact lens 32: 267-71.

58. Alfonso EC, Cantu-Dibildox J, Munir WM, Miller D, O'Brien TP, et al. (2006) Insurgence of Fusarium keratitis associated with contact lens wear. Arch Ophthalmol 124: 941-7.

59. Imamura Y, Chandra J, Mukherjee PK, Lattif AA, Szczotka-Flynn LB, et al. (2008) Fusarium and Candida albicans biofilms on soft contact lenses: model development, influence of lens type, and susceptibility to lens care solutions. Antimicrobial Agents Chemother 52: 171-82. 